\title{
Comprehensive Assessment of Protein and Excipient Stability in Biopharmaceutical Formulations Using $\mathrm{H}-1$ NMR Spectroscopy
}

DOI:

10.1021/acsptsci.0c00188

\section{Document Version}

Final published version

Link to publication record in Manchester Research Explorer

\section{Citation for published version (APA):}

Bramham, J. E., Podmore, A., Davies, S. A., \& Golovanov, A. P. (2021). Comprehensive Assessment of Protein and Excipient Stability in Biopharmaceutical Formulations Using H-1 NMR Spectroscopy. ACS Pharmacology \& Translational Science, 4(1), 288-295. https://doi.org/10.1021/acsptsci.0c00188

Published in:

ACS Pharmacology \& Translational Science

\section{Citing this paper}

Please note that where the full-text provided on Manchester Research Explorer is the Author Accepted Manuscript or Proof version this may differ from the final Published version. If citing, it is advised that you check and use the publisher's definitive version.

\section{General rights}

Copyright and moral rights for the publications made accessible in the Research Explorer are retained by the authors and/or other copyright owners and it is a condition of accessing publications that users recognise and abide by the legal requirements associated with these rights.

\section{Takedown policy}

If you believe that this document breaches copyright please refer to the University of Manchester's Takedown Procedures [http://man.ac.uk/04Y6Bo] or contact uml.scholarlycommunications@manchester.ac.uk providing relevant details, so we can investigate your claim.

\section{OPEN ACCESS}




\title{
Comprehensive Assessment of Protein and Excipient Stability in Biopharmaceutical Formulations Using ${ }^{1} \mathrm{H}$ NMR Spectroscopy
}

\author{
Jack E. Bramham, Adrian Podmore, Stephanie A. Davies, and Alexander P. Golovanov* \\ Cite This: ACS Pharmacol. Transl. Sci. 2021, 4, 288-295 \\ Read Online
}

ABSTRACT: Biopharmaceutical proteins are important drug therapies in the treatment of a range of diseases. Proteins, such as antibodies (Abs) and peptides, are prone to chemical and physical degradation, particularly at the high concentrations currently sought for subcutaneous injections, and so formulation conditions, including buffers and excipients, must be optimized to minimize such instabilities. Therefore, both the protein and small molecule content of biopharmaceutical formulations and their stability are critical to a treatment's success. However, assessing all aspects of protein and small molecule stability currently requires a large number of analytical techniques, most of which involve sample dilution or other manipulations which may themselves distort sample behavior. Here,

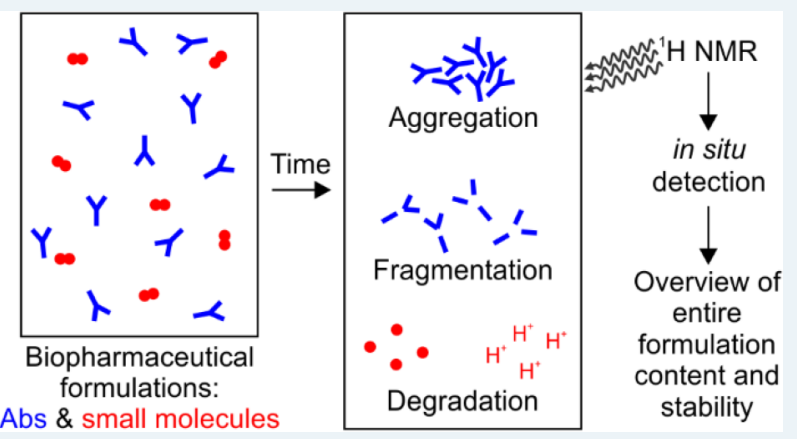
we demonstrate the application of ${ }^{1} \mathrm{H}$ nuclear magnetic resonance (NMR) spectroscopy to study both protein and small molecule content and stability in situ in high-concentration $(100 \mathrm{mg} / \mathrm{mL}) \mathrm{Ab}$ formulations. We show that protein degradation (aggregation or fragmentation) can be detected as changes in $1 \mathrm{D}^{1} \mathrm{H}$ NMR signal intensity, while apparent relaxation rates are specifically sensitive to $\mathrm{Ab}$ fragmentation. Simultaneously, relaxation-filtered spectra reveal the presence and degradation of small molecule components such as excipients, as well as changes in general solution properties, such as $\mathrm{pH}$. ${ }^{1} \mathrm{H}$ NMR spectroscopy can thus provide a holistic overview of biopharmaceutical formulation content and stability, providing a preliminary characterization of degradation and acting as a triaging step to guide further analytical techniques.

KEYWORDS: biopharmaceutical formulation, NMR spectroscopy, excipients, fragmentation, aggregation

\section{INTRODUCTION}

Biopharmaceutical antibodies (Abs), such as monoclonal antibodies (mAbs) and, more recently, bispecific antibodies (BsAbs), are increasingly important therapies in the treatment of a wide range of diseases, including cancer, arthritis, and diabetes. Within the biopharmaceutical industry, there is considerable interest in the development of high-concentration $(>100 \mathrm{mg} / \mathrm{mL})$ protein formulations to enable subcutaneous administration of the lowest possible volume injection, ${ }^{1,2}$ potentially by the patient themselves. ${ }^{3}$ Such administration strategies result in lower treatment costs and better patient experience, particularly in the treatment of chronic conditions such as autoimmune disorders. ${ }^{4}$ However, high protein concentrations are associated with increased levels of physical instabilities, such as self-association, ${ }^{5,6}$ aggregation, ${ }^{7}$ and liquid-liquid phase separation (LLPS), ${ }^{8-10}$ in addition to chemical degradation, such as fragmentation ${ }^{11,12}$ and oxidation.

To ensure therapeutic proteins remain stable and therefore safe and efficacious at high concentrations, formulation conditions, such as buffers, $\mathrm{pH}$, ionic strength, and small molecule excipients, must be optimized. ${ }^{13,14}$ In this regard, the long-term stabilities of both the protein molecules themselves and the small molecule formulation components are important. Degradation of the small molecule components required for protein stability, ${ }^{15,16}$ or their reaction with proteins, ${ }^{17,18}$ may subsequently lead to protein instabilities. Optimisation of formulation conditions, and continued assessment of formulation stability, requires analytical techniques capable of assessing both protein and small molecule content and behavior, ideally in situ in intact formulations. However, in practice, a wide range of techniques is deployed, ${ }^{19-21}$ and these techniques typically require manipulation of highconcentration formulations, such as dilution, addition of a probe molecule, or salt removal, potentially leading to changes in protein and small molecule structure and behavior.

Nuclear magnetic resonance (NMR) spectroscopy is a powerful biophysical technique, which can be applied in situ at high concentration without sample dilution. The range of

Received: November 4, 2020

Published: December 16, 2020 
NMR experiments, from saturation transfer for detection of protein-excipient interactions ${ }^{22,23}$ to diffusion and relaxation assessment of $\mathrm{mAb}$ solution behavior, ${ }^{24,25}$ and fingerprinting of higher-order structures of mAbs and biosimilars ${ }^{26-28}$ mean that NMR can be used to study a wide range of biopharmaceutical problems. In formulation studies, NMR has been used to characterize the presence of residual small molecule contaminants from bioprocessing ${ }^{29,30}$ and to quantify small molecule levels, ${ }^{31}$ while low resolution benchtop spectroscopy has been applied to study mAb degradation based on broad changes in the relaxation rate of the water signal. ${ }^{32,33}$ For complex formulations, there may be advantages in observing multiple parameters to characterize multiple degradation pathways, and, in principle, high-resolution ${ }^{1} \mathrm{H}$ NMR allows observation of all proton containing species, including proteins and small molecules.

Here, we explore the use of high-resolution ${ }^{1} \mathrm{H}$ NMR spectroscopy to report on the content and behavior of both small molecule and $\mathrm{Ab}$ protein components simultaneously in model formulations. For three high-concentration Abs (100 $\mathrm{mg} / \mathrm{mL}$ ) stored under stressed stability conditions $\left(40{ }^{\circ} \mathrm{C}\right)$, we demonstrate that complex ${ }^{1} \mathrm{H}$ NMR spectra of $\mathrm{Ab}$ solutions can be separated into small molecule and protein regions by the application of a simple transverse relaxation $\left(T_{2}\right)$ filter. Having spectroscopically separated protein and small molecule components, we show that the signal intensities and apparent relaxation rates of Abs can be used to monitor protein stability and the occurrence of degradation, such as aggregation and fragmentation, over a 12-week period. NMR observations are compared with a standard size-exclusion chromatography analysis. Additionally, the appearance, intensity, and chemical shift of small molecule components can be simultaneously used to study the presence and degradation of excipients themselves, as well as changes in general solution properties, such as $\mathrm{pH}$. Through the use of sealed NMR tubes with coaxial inserts, these assessments are observed in situ at high concentration without sample dilution or manipulation. We demonstrate that ${ }^{1} \mathrm{H}$ NMR spectroscopy is a suitable orthogonal technique to provide a comprehensive overview of formulation content and stability and can act as a triaging step to guide further detailed analysis.

\section{MATERIALS AND METHODS}

Sample Preparation. Two mAbs and a BsAb were supplied by AstraZeneca: COE-03 (IgG1, MW 144.8 kDa, pI 8.44), COE-07 (bispecific IgG1, MW 196.7 kDa, pI 8.0), and COE-19 (IgG1, MW $148 \mathrm{kDa}, \mathrm{pI}$ 7.4-7.9). All Abs were dialyzed (six buffer exchanges over 3 days) into $20 \mathrm{mM}$ phosphate buffer, $\mathrm{pH} 6.5$ (sodium phosphate dibasic $\left(\mathrm{Na}_{2} \mathrm{HPO}_{4}\right)$ and sodium phosphate monobasic $\left(\mathrm{NaH}_{2} \mathrm{PO}_{4}\right)$ (both Sigma-Aldrich)), with $200 \mathrm{mM} \mathrm{NaCl}$ (Fisher) in GeBAflex-Maxi-tubes (MWCO $8 \mathrm{kDa}$, Generon, rinsed with $20 \%$ ethanol and then distilled water). Small molecules from the original formulations remaining after this extensive dialysis, and the phosphate buffer with $\mathrm{NaCl}$, were treated as the final model formulations. Sample concentration was conducted in Vivaspin 20 centrifugal concentrators (MWCO $30 \mathrm{kDa}$, Sartorius), with final solutions filtered using $0.22 \mu \mathrm{m}$ filters (PVDF, Merck Millipore). Concentration measurements were based on absorbance at $280 \mathrm{~nm}$ (A280) using known extinction coefficients and a NanoDrop spectrophotometer (Thermo Scientific).
All samples were prepared to $100 \mathrm{mg} / \mathrm{mL}$ protein concentration, with $0.05 \%$ sodium azide (Fisher) added to prevent bacterial growth. Samples for NMR spectroscopy (400 $\mu \mathrm{L}$ ) were prepared in triplicate and placed in $5 \mathrm{~mm}$ borosilicate glass NMR tubes (Wilmad-LabGlass), with a coaxial insert (50 $\mathrm{mm}$ stem height, Wilmad-LabGlass) containing $60 \mu \mathrm{L}$ of ${ }^{2} \mathrm{H}_{2} \mathrm{O}$ (Sigma-Aldrich) to provide a spectrometer lock without sample dilution or change in formulation. Samples (one per time point) for HPSEC were placed in borosilicate glass vials (Sigma-Aldrich, $1 \mathrm{~mL}$ ). All samples were sealed with an appropriate cap and Parafilm wrap (Cole-Parmer) and stored upright at $40{ }^{\circ} \mathrm{C}$ in a Heratherm compact incubator (Thermo Scientific, uniformity $\pm 1.2{ }^{\circ} \mathrm{C}$, stability $\pm 0.2^{\circ} \mathrm{C}$ ). One non-NMR sample per $\mathrm{Ab}$ was frozen at each time point for analysis at a later date.

NMR Spectroscopy. NMR experiments were acquired at $40{ }^{\circ} \mathrm{C}$ using a Bruker $800 \mathrm{MHz}$ Avance III spectrometer equipped with a $5 \mathrm{~mm}$ TCI cryoprobe and variable temperature control unit, with temperature calibrated against a standard methanol sample and verified with an external thermocouple placed in a sample tube.

${ }^{1} \mathrm{H}$ 1D spectra were recorded using WATERGATE water suppression (p3919gp Bruker pulse program), with this water suppression also used in relaxation experiments. Longitudinal relaxation rates $\left(R_{1}\right)$ were measured using the standard Bruker inversion recovery sequence ( $\mathrm{t} 1 \mathrm{ir})$, with 10 recovery delays ranging from $1 \mathrm{~ms}$ to $3 \mathrm{~s}$. Transverse relaxation rates $\left(R_{2}\right)$ were measured using a Carr-Purcell-Meiboom-Gill (CMPG) sequence, with temperature compensation to ensure equal sample heating during the CPMG acquisition and a fixed echo time of $3.6 \mathrm{~ms}$. $\mathrm{T}_{2}$-filtered spectra were extracted from the CPMG data, with 32 echoes producing a 116 ms relaxation filter.

Spectra were processed and analyzed using Topspin 4.0 (Bruker). Apparent ${ }^{1} \mathrm{H}$ longitudinal and transverse relaxation rates at spectral points ( $0.05 \mathrm{ppm}$ intervals) across the spectral width were calculated in Dynamics Center 2.6 (Bruker). Relaxation rates were fitted to single component models, with two or more component models not significantly improving fitting. The processed data were plotted in GraphPad Prism 6.0.

High Performance Size Exclusion Chromatography. Analysis of $\mathrm{mAb}$ and $\mathrm{BsAb}$ monomeric, aggregate, and fragment species was performed using high performance size exclusion chromatography (HPSEC). This was performed using an Agilent 1200 system with a TSKgel SW $\mathrm{XL}_{\mathrm{XL}}$ column (30 $\mathrm{cm} \times 7.8 \mathrm{~mm}, 5 \mu \mathrm{m}$ particle size, Tosoh Bioscience). Samples were diluted to $10 \mathrm{mg} / \mathrm{mL}$ and $0.45 \mu \mathrm{m}$ filtered prior to assessment with centrifugal filters (Ultrafree-MC-HV, Merck Millipore). Twenty-five $\mu \mathrm{L}$ was injected each time, and the system was run at $1.0 \mathrm{~mL} / \mathrm{min}$, with a mobile phase of $0.1 \mathrm{M}$ $\mathrm{Na}_{2} \mathrm{HPO}_{4}, 0.1 \mathrm{M} \mathrm{Na}_{2} \mathrm{SO}_{4}, \mathrm{pH}$ 6.8. The absorbance wavelength for detection was set at $280 \mathrm{~nm}$. Chromatograms were analyzed in ChemStation (Agilent).

\section{RESULTS}

Initial NMR Characterization of Formulation Content. Protein formulations are routinely stored at elevated temperatures to trigger degradation and infer long-term formulation stability. Here, we used this stressed stability approach to explore how ${ }^{1} \mathrm{H}$ NMR spectroscopy can be used to study the content and stability of nonlabeled Abs samples, such as those obtained from mammalian production pipelines which do not 
permit easy isotope labeling. First, the initial baseline ${ }^{1} \mathrm{H}$ NMR spectra and parameters were recorded for each of the three $A b$ formulations at $40{ }^{\circ} \mathrm{C}$ (at time $t=0$ ). The acquired NMR spectra represent a complex mixture of overlapping protein and small molecule signals (Figure 1A). Despite this overlap, some

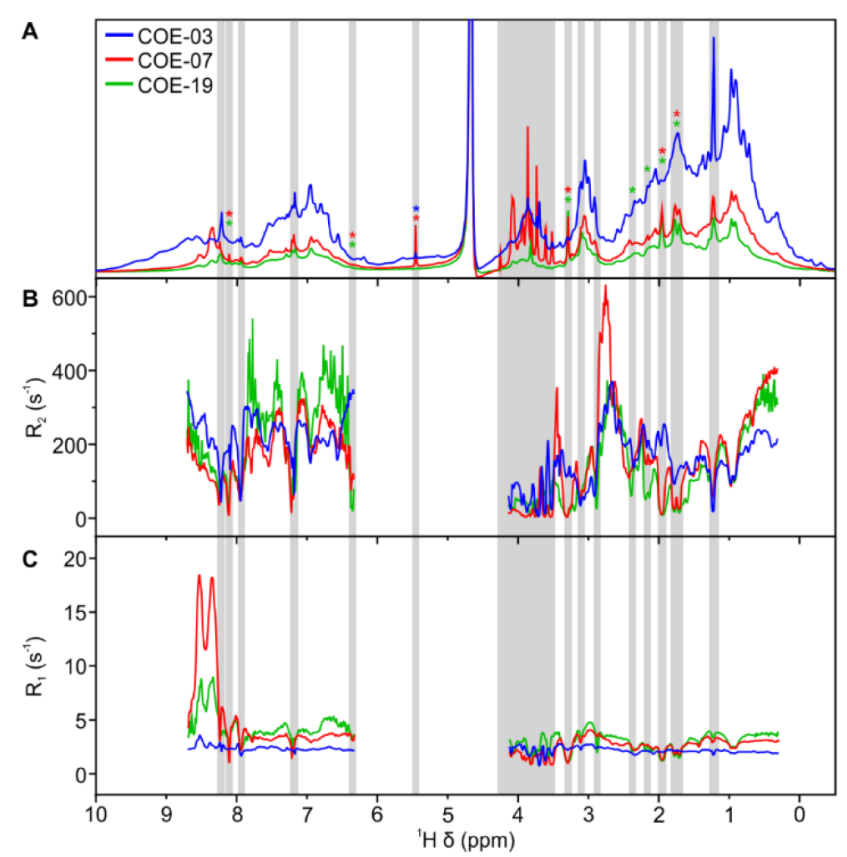

Figure 1. Initial NMR spectra and relaxation rates of the three Abs recorded at $40{ }^{\circ} \mathrm{C}$. (A) ${ }^{1} \mathrm{H}$ NMR spectra overlay of COE-03 (blue), COE-07 (red), and COE-19 (green). Apparent $R_{2}$ (B) and $R_{1}(\mathrm{C})$ were measured for each spectral point. Mean rates were from triplicate samples. Gray areas include signals arising from small molecule components. Colored asterisks indicate small molecules present in specified $\mathrm{Ab}$ samples only. Blank regions in apparent relaxation spectra were excluded due to low signal and large measurement errors. Residual water signal at $4.7 \mathrm{ppm}$.

spectral regions are clearly dominated by sharper, more intense signals arising from small molecules, which are also often present in much larger concentrations. As measuring individual proton longitudinal $\left(R_{1}\right)$ or transverse $\left(R_{2}\right)$ relaxation rates is impossible, we measured the apparent relaxation rates for each point in the spectra at $0.05 \mathrm{ppm}$ intervals, thus providing a characteristic relaxation profile for each formulation (Figure $1 \mathrm{~B}, \mathrm{C})$. As large and small molecules have significantly different tumbling rates, their $R_{2}$ 's are also significantly different. Factoring that excipients and small molecules have an $R_{2}<$ $75 \mathrm{~s}^{-1}$, the spectra can be classified into regions dominated by $\mathrm{Ab}$ signals (shown in white) and small molecules (shown in gray).

In the protein-dominated regions of ${ }^{1} \mathrm{H}$ spectra (Figure 1A), the three Abs display markedly different signal intensities despite identical protein concentrations and similar formulations. COE-07 and COE-19 signals generally exhibited faster relaxation rates than COE-03 (Figure 1B,C). These spectra and parameters indicate that COE-07 and COE-19 exhibit greater self-association than COE-03, in agreement with previous observations of the three Abs' behavior. ${ }^{34}$ Noticeably, despite the differences elsewhere, the characteristic $A b$ methyl signals at $0.9-1.0 \mathrm{ppm}$ result in similar $R_{1}$ and $R_{2}$ values for all three Abs, suggesting this invariant spectral region represents a flexible structural feature common to all Abs tested. Addition- ally, $R_{1}$ values in the protein spectral region around $8.5 \mathrm{ppm}$ appear acutely sensitive to differences between the Abs.

The presence of small molecule components (shaded gray in Figure 1) is easily identified by their slow $R_{2}$, and their separated spectra is most conveniently obtained by running $T_{2}$ filtered experiments ${ }^{30}$ (Figure $\mathrm{S} 1$ ). These $\mathrm{T}_{2}$-filtered spectra reveal the presence of residual components from the original formulations which were not completely removed by multiple rounds of dialysis during sample preparation-histidine in all three Abs, sucrose in COE-03 and COE-07, and arginine in COE-07 and COE-19. Additionally, trace ethanol was present in all $\mathrm{Ab}$ solutions, likely carried over from washing dialysis membranes before use. Protein translational diffusion $\left(D_{\mathrm{L}}\right)$, in principle, may also report on molecular size; ${ }^{25}$ however, for such concentrated $\mathrm{Ab}$ solutions, the quality of ${ }^{1} \mathrm{H}$ DOSY spectra was very poor for $\mathrm{Ab}$ signals (data not shown) due to particularly fast relaxation and slow diffusion. Therefore, relaxation profiling using $R_{1}$ and $R_{2}$ values provides a sensitive alternative for characterizing highly concentrated $\mathrm{Ab}$ formulations.

Changes in Ab 1D ${ }^{1} \mathrm{H}$ NMR Spectra upon Accelerated Stability Storage. Having acquired baseline spectra and parameters for the $\mathrm{Ab}$ and small molecule components at the initial time point, NMR experiments were subsequently acquired after $1,2,3,4,8$, and 12 weeks storage at $40{ }^{\circ} \mathrm{C}$ for the same sealed samples. $1 \mathrm{D}^{1} \mathrm{H}$ NMR spectra represent the simplest and fastest acquired experiments, so they may provide the easiest assessment of $\mathrm{Ab}$ stability. The ${ }^{1} \mathrm{H}$ NMR spectra of COE-07 and COE-19 exhibit increases in signal intensity with time (Figure 2), indicating protein degradation. Noticeably, the upscaled spectra of these Abs retain the same overall shape as the initial spectra. As the amount of material present in the sample remains the same, the broad increase in signal intensity across the spectra for COE-07 and COE-19 suggests

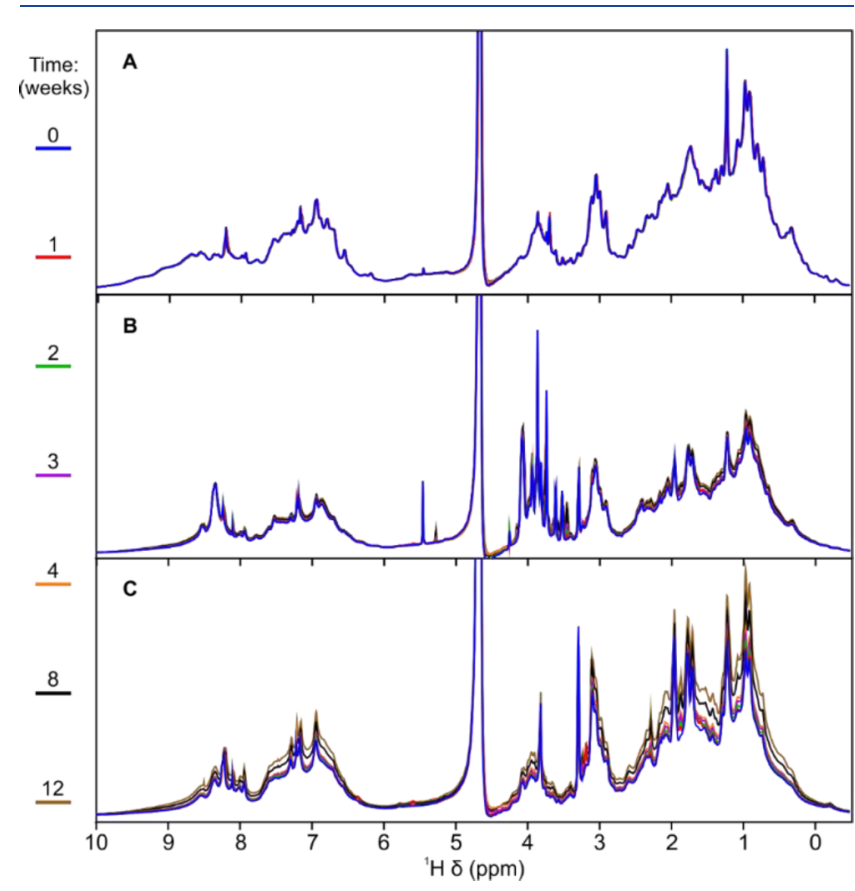

Figure 2. Changes in ${ }^{1} \mathrm{H}$ NMR spectra during accelerated stability storage at $40{ }^{\circ} \mathrm{C}$ over time. (A) COE-03, (B) COE-07, and (C) COE19. Spectra for COE-07 and COE-19 are scaled up for clarity 2-fold and 3-fold, respectively, compared to COE-03 spectra. 
predominantly fragmentation occurring, resulting in smaller freely tumbling $\mathrm{Ab}$ domains. These retain the same general spectral profile as the intact $\mathrm{Ab}$ due to the same domain fold but have higher apparent signal intensity due to their smaller molecular weight and hence faster rotational correlation time $\left(\tau_{c}\right)$. Conversely, COE-03 spectra were largely unchanged, even after 12 weeks storage at $40{ }^{\circ} \mathrm{C}$.

We have previously shown that protein aggregation results in decreases in observed signal intensities as slower-tumbling or NMR-invisible species are formed. ${ }^{35}$ Therefore, the predominant changes in NMR signal intensity for a given sample reveal the predominant underlying $\mathrm{Ab}$ degradation process, with increasing and decreasing intensities reflecting fragmentation and aggregation, respectively. In a more complex scenario, if both fragmentation and aggregation occur simultaneously, then it may be envisaged that opposing changes in intensity may largely balance each other (see Figure S2 for illustrative modeling). As we will show, this is the case for COE-03, where no significant change in intensity is observed (Figure 2A). In such a situation, additional spectral considerations need to be taken into account to correctly interpret whether no degradation has occurred, or whether fragmentation and aggregation have occurred simultaneously.

Changes in Protein Apparent Relaxation Rates during Accelerated Stability Storage. Given the potential complex behavior of $1 \mathrm{D}{ }^{1} \mathrm{H}$ NMR spectra in response to degradation, we next considered changes in apparent relaxation rates. Large protein aggregates, such as those resulting from $>150 \mathrm{kDa}$ Abs, with slow $\tau_{\mathrm{c}}$ and rapid $R_{2}$ are likely largely "NMR-invisible" and, as such, make a negligible contribution to the measured apparent rates. Conversely, small protein species with faster tumbling are expected to contribute more prominently. For all three Abs, the apparent $R_{2}$ values for protein-dominated spectral regions show a tendency to decrease with storage time (Figure 3). The reductions in $\mathrm{Ab}$
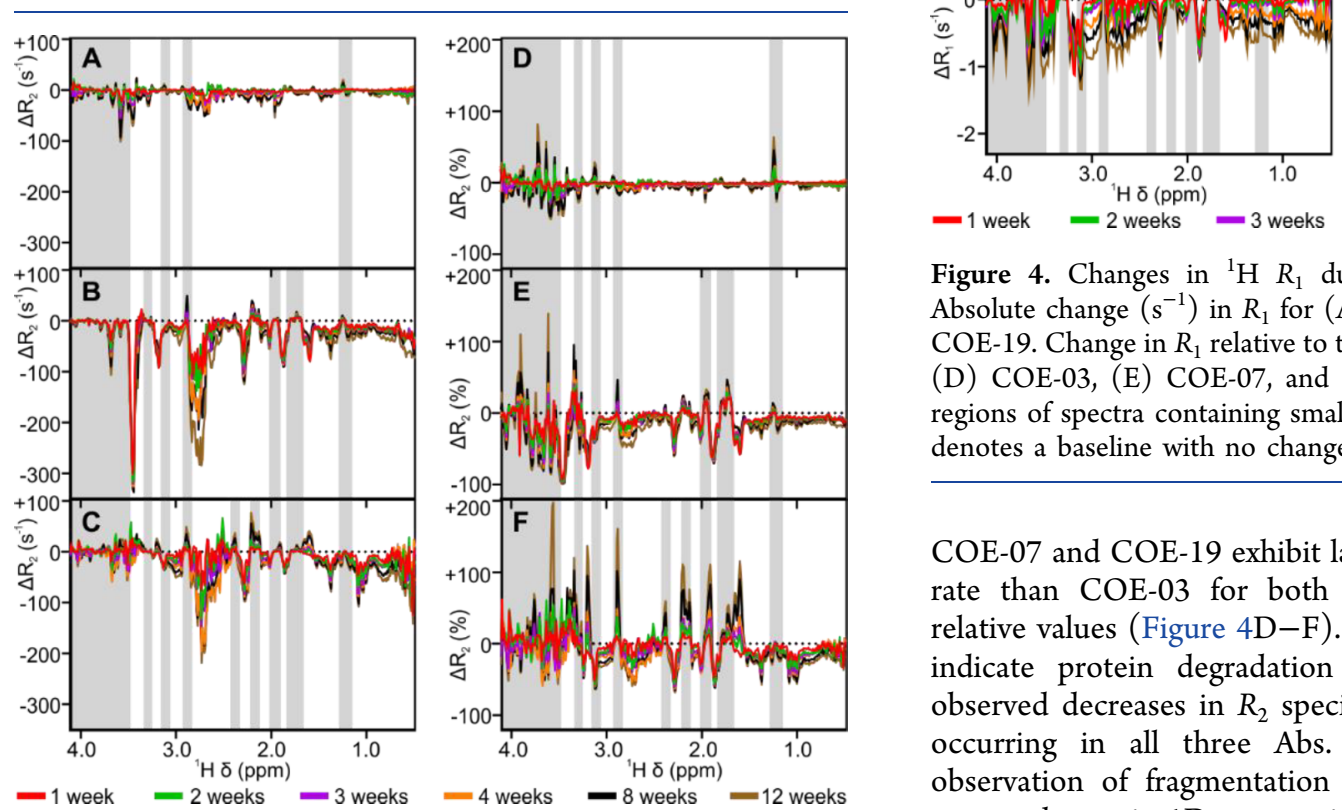

$R_{2}$ with time are larger for COE-07 and COE-19 than for COE-03, both for absolute values (Figure $3 \mathrm{~A}-\mathrm{C}$ ) and for relative values expressed as a percentage of the original $R_{2}$ values (Figure $3 \mathrm{D}-\mathrm{F}$ ). As the $R_{2}$ rate for a large protein is roughly proportional to the molecular size, the observed decreases in $R_{2}$ are consistent with an average decrease in the molecular size of the observed species, i.e., the occurrence of protein fragmentation. In this respect, the changes in absolute $R_{2}$ values for the spectral region around $2.8 \mathrm{ppm}$ appear to be particularly sensitive to fragmentation given its relatively high initial $R_{2}$ for all three Abs. The behavior in spectral regions dominated by small molecule signals is more complex and cannot be interpreted based solely by $R_{2}$ values. Our further analysis (below) reveals chemical changes occurring for these formulation components.

$R_{1}$ values are more complex to interpret than $R_{2}$ in terms of molecular tumbling rates, given the $\mathrm{V}$-shaped relationship between $\tau_{\mathrm{c}}$ and longitudinal relaxation. Here, all $\mathrm{Ab}$ signals exhibit reductions in $R_{1}$ rates with time which are fairly linear across the breadth of the Ab NMR spectra (Figure 4). Again,
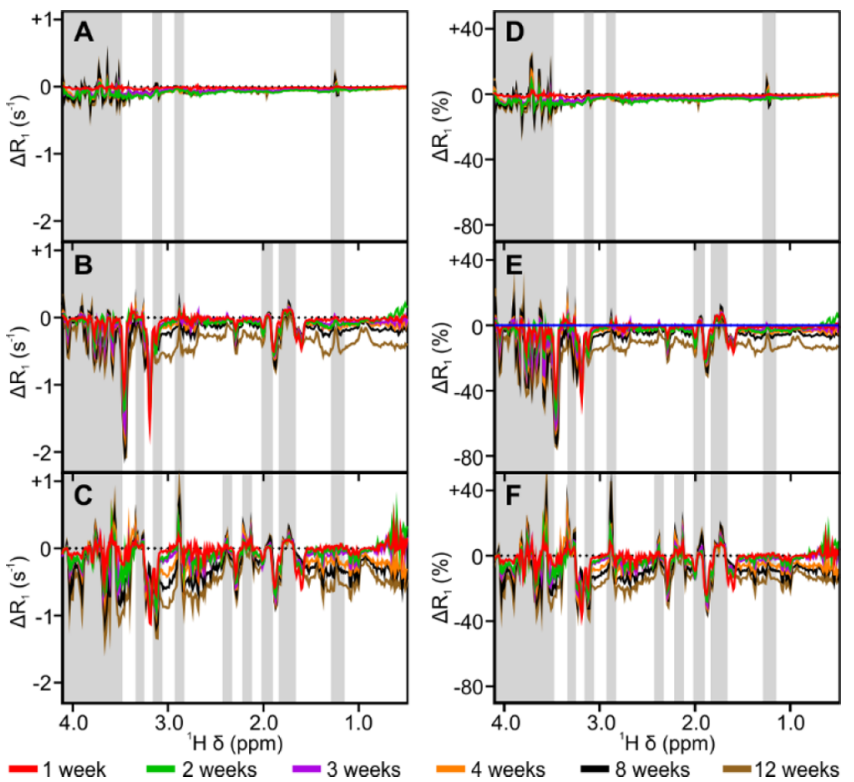

Figure 4. Changes in ${ }^{1} \mathrm{H} R_{1}$ during accelerated stability storage. Absolute change $\left(\mathrm{s}^{-1}\right)$ in $R_{1}$ for (A) COE-03, (B) COE-07, and (C) COE-19. Change in $R_{1}$ relative to the initial value at time $t=0$ (\%) for (D) COE-03, (E) COE-07, and (F) COE-19. Gray areas highlight regions of spectra containing small molecule signals. The dotted line denotes a baseline with no change.

COE-07 and COE-19 exhibit larger decreases in the relaxation rate than COE-03 for both absolute (Figure 4A-C) and relative values (Figure $4 \mathrm{D}-\mathrm{F}$ ). Together, both relaxation rates indicate protein degradation for all three Abs, with the observed decreases in $R_{2}$ specifically indicating fragmentation occurring in all three Abs. Therefore, for COE-03, the observation of fragmentation based on relaxation rates, yet no net change in $1 \mathrm{D}$ spectra, infers that aggregation must also be occurring for this mAb. For COE-07 and COE-19, the NMR observables show the predominant occurrence of fragmentation but do not rule out aggregation in these two Abs.

Protein Degradation Detected by High-Performance Size Exclusion Chromatography Analysis. To relate NMR 
observations of $\mathrm{Ab}$ stability with standard orthogonal measurements, we analyzed the monomer, aggregate, and fragment content using high performance size exclusion chromatography (HPSEC) (see Figure S3 for chromatograms) of Ab samples stored in identical formulations under identical conditions (Figure 5). All three Abs exhibited both fragmentation and
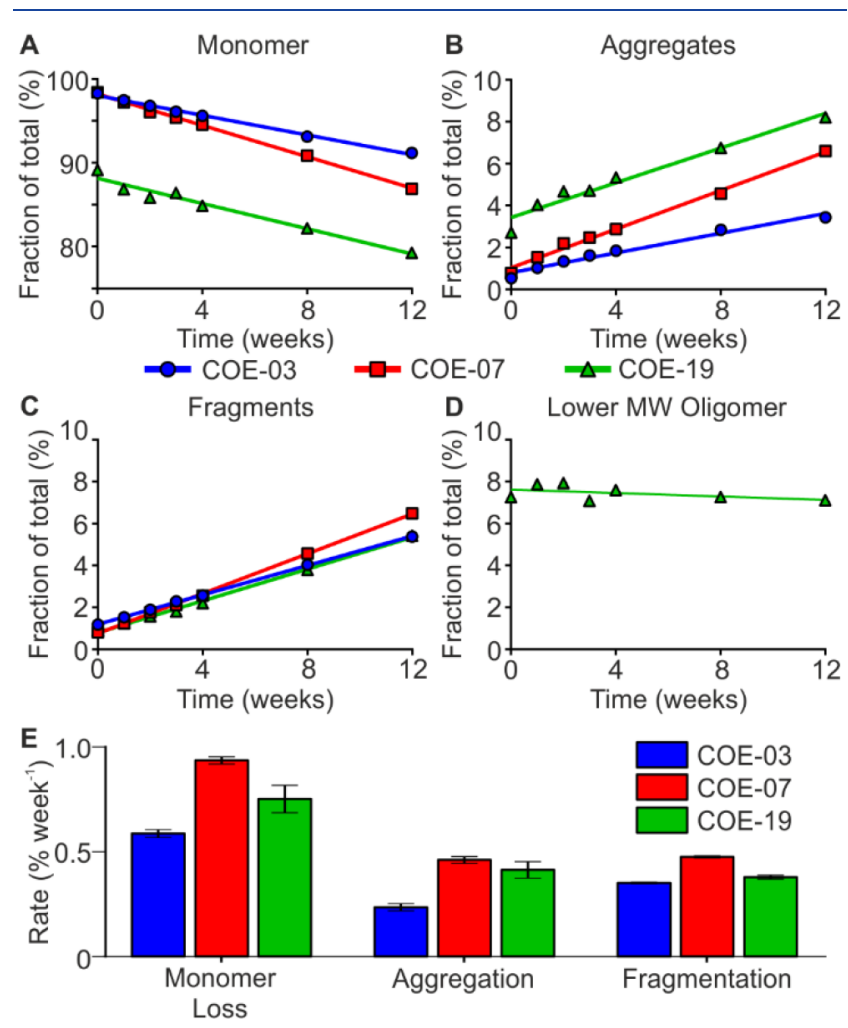

Figure 5. Assessment of monomer, aggregate, and fragment content by HPSEC. Monomer (A), aggregate (B), and fragment (C) species as a percentage of total observed species. (D) Lower molecular weight oligomer detected in COE-19. Experimental data with linear fit. (E) Rates of monomer loss, aggregation, and fragmentation per week, derived from linear fits with $95 \%$ confidence intervals.

aggregation in a time-dependent manner, with the rates of aggregation and fragmentation slowest for COE-03. Additionally, a lower molecular weight oligomer and a higher initial level of aggregates were detected in COE-19 samples (Figure 5D). This concurs with lower observed initial 1D NMR signal intensity for COE-19, with these oligomers expected to contribute less to the observable signal (Figure 1). Overall, the NMR observations of protein degradation are in agreement with the HPSEC measurements, with NMR spectra sensitive to protein degradation occurring at a rate of $<1 \%$ per week.

Small Molecule Degradation Detected by $T_{2}$-Filtered ${ }^{1} \mathrm{H}$ NMR. Along with stability of the biopharmaceutical protein itself, the stability of small molecule components such as buffers and excipients is critical to the overall formulation. With this in mind, the NMR signals from the residual small molecule components from the original $\mathrm{Ab}$ formulations were monitored using $\mathrm{T}_{2}$-filtered experiments ( $116 \mathrm{~ms}$ filter), which essentially remove signals from the faster relaxing protein. Over time a number of small molecules exhibited changes in NMR signals associated with degradation. In COE-03 and COE-07 samples, sucrose (not present in COE-19) exhibited reduction in glycosyl $\mathrm{C} 1-{ }^{1} \mathrm{H}$ signal intensity, accompanied by appearance and increases in glucose $\mathrm{C} 1{ }^{-1} \mathrm{H}$ signal (Figure 6A,B). This degradation was markedly greater in COE-07 than in COE-03

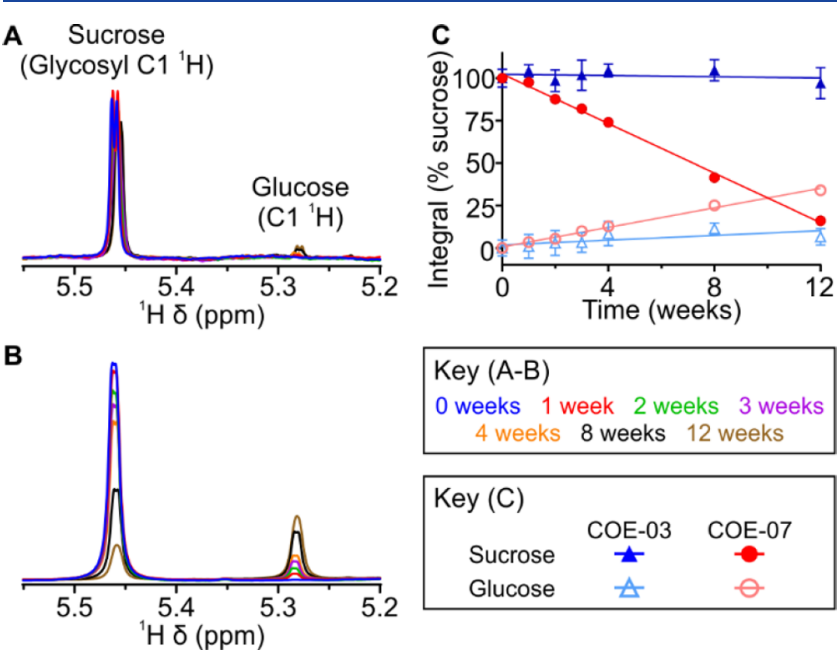

Figure 6. Degradation of sucrose detected by ${ }^{1} \mathrm{H}$ NMR spectroscopy. ${ }^{1} \mathrm{H}$ NMR spectra for (A) COE-03 and (B) COE-07, with sucrose (glycosyl $\left.\mathrm{C} 1-{ }^{1} \mathrm{H}\right)$ and glucose $\left(\mathrm{C} 1-{ }^{1} \mathrm{H}\right)$ at 5.46 and $5.28 \mathrm{ppm}$, respectively. (C) Change in sucrose and glucose integrals (expressed as a percentage of the initial sucrose integral in each Ab sample) over time. Mean \pm SD for three replicates, with linear fit.

(Figure 6C). Notably in COE-07 samples, increases in glucose signal were not proportional with sucrose signal reduction, as would be expected from the breakdown of one sucrose molecule into one molecule of glucose and one molecule of fructose. This indicates further degradation of glucose in COE07 , potentially in the form of glycation of protein molecules.

${ }^{1} \mathrm{H}$ NMR also detected degradation of arginine present in COE-07 and COE-19 formulations (not present in COE-03) (Figure $7 \mathrm{~A}, \mathrm{~B})$. Here, reduction in arginine signals was accompanied by the appearance of new upfield resonances, consistent with the arginine oxidation. ${ }^{36}$ Arginine degradation occurred at similar levels in both Ab solutions. Finally,
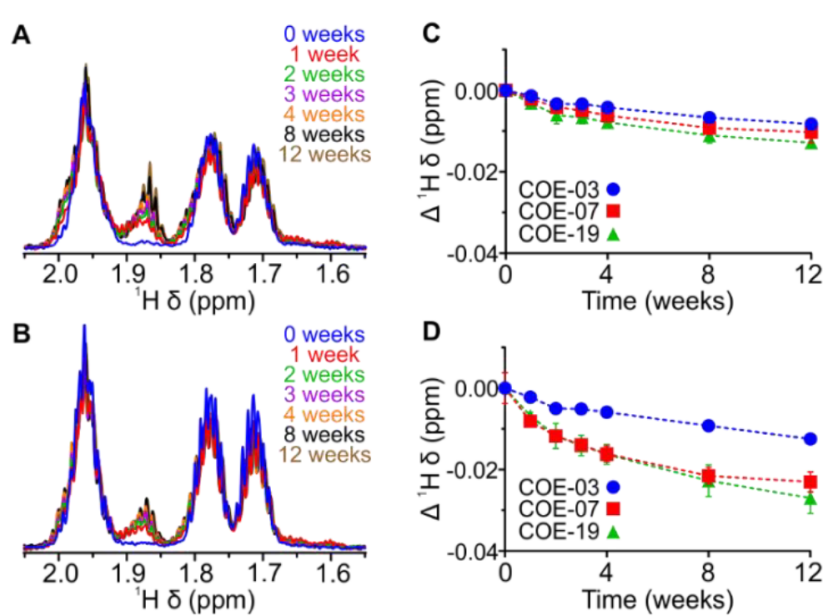

Figure 7. Arginine degradation and solution $\mathrm{pH}$ changes detected by ${ }^{1} \mathrm{H}$ NMR spectroscopy. ${ }^{1} \mathrm{H}$ NMR spectral region containing arginine signals (C $\beta$ - and $\mathrm{C}^{-1}{ }^{1} \mathrm{H}$ 's) for (A) COE-07 and (B) COE-19. Changes $(\Delta)$ in ${ }^{1} \mathrm{H}$ chemical shifts for histidine $\mathrm{C}_{\delta 2}{ }^{1} \mathrm{H}(\mathrm{C})$ and $\mathrm{C}_{\varepsilon 1}{ }^{1} \mathrm{H}$ (D) over the course of the stability study. Mean \pm SD for three replicates, with dashed lines as guides only. 
histidine present in all $\mathrm{Ab}$ samples exhibited minor upfield shifts in both imidazole carbon bound protons (Figure 7C,D). These signals are sensitive to solution $\mathrm{pH}$ as a result of imidazole ring protonation, and as such these changes suggest a slight increase $\left(\sim 0.1 \mathrm{pH}\right.$ units based on calibration curves $\left.{ }^{37}\right)$ in solution $\mathrm{pH}$ over the 12-week period. All together the data suggests that comprehensive analysis of even a simple set of NMR spectra, including ${ }^{1} \mathrm{H} 1 \mathrm{D}$, supplemented by $R_{1}$ and $R_{2}$ relaxation profiles and $T_{2}$-filtered $1 D$ experiments, can provide a comprehensive assessment of protein formulations and reveal degradation of both protein and small molecules.

\section{DISCUSSION}

Monitoring both small molecule and protein content and stability is vital to the successful optimization of $\mathrm{Ab}$ formulations and achieving a long product shelf life. However, assessment of formulations typically requires numerous techniques, with separate sample manipulations which may distort the analysis; for example, sample dilution would alter the equilibrium of reversible self-association present in the original formulation. We show here that ${ }^{1} \mathrm{H}$ NMR spectroscopy can be used as an orthogonal technique to simultaneously characterize the content and stability of both protein and small molecule formulation components, perhaps as a triaging approach to inform decisions on which specialized techniques should be employed to quantify or study particular forms of degradation in more detail.

In $\mathrm{NMR}$, initial $\mathrm{Ab}$ signal intensity and relaxation rates report on $\mathrm{Ab}$ solution behavior, with molecules exhibiting greater self-association or with oligomer species displaying lower signal intensities and higher relaxation rates (Figure 1). Following degradation at $40^{\circ} \mathrm{C}$, the observed broad increases in $\mathrm{Ab}$ signal intensity with retention of the overall spectral appearance (Figure 2) indicate fragmentation in COE-07 and COE-19. This is consistent with previous comparisons of enzymatically digested $\mathrm{mAb}$ fragments with intact $\mathrm{mAbs}$ by $2 \mathrm{D}$ natural abundance NMR. ${ }^{27}$ Conversely, $1 \mathrm{D}$ spectra may exhibit reductions in intensity if aggregation is dominant. ${ }^{35}$ However, as $1 \mathrm{D}^{1} \mathrm{H}$ NMR spectra represent a balance between monomers, aggregates, and fragments, such spectra coincidentally may be insensitive to degradation if the effects of aggregation and fragmentation on signal intensity cancel each other out (Figure S2), as in the case of COE-03 here (Figures 2 and 5). However, the addition of relaxation rate analysis revealed that fragmentation occurred in COE-03 (Figures 3 and 4), which, with the observed static 1D spectra, was allowed to infer the occurrence of aggregation. For the two other Abs, 1D spectral changes revealed the presence of significant degradation immediately. As protein and small molecule signals are monitored simultaneously, this more detailed approach may be advantageous compared to recently suggested analysis based on the single parameter relaxation rate of the water signal. ${ }^{33,38}$ Our approach could also be extended to study chemical modification of $\mathrm{Abs}^{39,40}$ and small molecule formulation components at the same time, alongside $\mathrm{Ab}$ degradation.

Small molecules, such as buffers and excipients, are also an integral component of biopharmaceutical formulations, responsible for stabilizing and solubilizing the therapeutic protein. If they degrade, their stabilizing function may be diminished. Most common buffers and excipients contain NMR observable protons. ${ }^{31}$ As demonstrated here, ${ }^{1} \mathrm{H}$ NMR is well suited to monitoring the presence and degradation of small molecules, particularly after the application of a $\mathrm{T}_{2}$ filter to remove fast relaxing protein signals (Figures 6 and 7). This is particularly applicable to studying the degradation of sacrificial excipients, such as methionine $e^{41,42}$ and other antioxidants, which are believed to protect proteins from degradation by undergoing degradation themselves. Additionally, the chemical shift of ionizable species, such as buffer molecules (e.g., histidine here) or spiked into solution as a tracer, can be used as an inbuilt $\mathrm{pH}$ meter (Figure 7) when compared to a known calibration curve. These assessments of small molecule stability may be coupled with the NMR identification of small molecule contaminants or processing impurities $^{29,30}$ to provide an overarching assessment of the small molecule content of solutions throughout the manufacturing process.

\section{CONCLUSION}

NMR assessment of both protein and small molecule components provides a holistic characterization of the content and stability of an overall biopharmaceutical formulation. Observation of changes in protein signal intensity or apparent relaxation rates indicate that monomer, aggregate, and fragment content should be investigated, for example, by HPSEC or capillary gel electrophoresis (CGE). Changes in excipient signal intensity or chemical shift or appearance of new signals indicates chemical degradation of small molecules. After detection of degradation of specific small molecules, such as sucrose degradation into glucose observed here, specific protein modifications, such as protein glycation which may impact pharmacokinetics and pharmacodynamics, ${ }^{43,44}$ should be investigated. This NMR assessment of small molecule and protein content and stability can be performed in situ at high concentration without further sample manipulation, making it a useful orthogonal assessment of overall formulation stability and helping to triage the use of specialized techniques for more detailed characterization.

\section{ASSOCIATED CONTENT}

\section{Supporting Information}

The Supporting Information is available free of charge at https://pubs.acs.org/doi/10.1021/acsptsci.0c00188.

Figure $\mathrm{S} 1, \mathrm{~T}_{2}$-filtered NMR spectra at $T=0$; Figure $\mathrm{S} 2$, illustrative modeling of effect of $\mathrm{Ab}$ aggregation and fragmentation on NMR signal intensity; and Figure S3, HPSEC chromatograms showing Ab degradation (PDF)

\section{AUTHOR INFORMATION}

\section{Corresponding Author}

Alexander P. Golovanov - Manchester Institute of Biotechnology and School of Chemistry, Faculty of Science and Engineering, The University of Manchester, Manchester M1 7DN, U.K.; $\odot$ orcid.org/0000-0002-8592-3984; Email: a.golovanov@manchester.ac.uk

\section{Authors}

Jack E. Bramham - Manchester Institute of Biotechnology and School of Chemistry, Faculty of Science and Engineering, The University of Manchester, Manchester M1 7DN, U.K.

Adrian Podmore - Dosage Form Design \& Development, BioPharmaceuticals Development, RњD, AstraZeneca, Cambridge CB21 6GH, U.K. 
Stephanie A. Davies - Dosage Form Design \& Development, BioPharmaceuticals Development, R\&D, AstraZeneca, Cambridge CB21 6GH, U.K.

Complete contact information is available at:

https://pubs.acs.org/10.1021/acsptsci.0c00188

\section{Author Contributions}

J.E.B. performed experiments, analyzed the data, and drafted the manuscript. A.P. and S.A.D. supplied the samples and provided the guidance and supervision from the industry's perspective. A.P.G. conceived and supervised the project and provided input regarding data analysis. The manuscript was written through contributions of all authors. All authors have given approval to the final version of the manuscript.

\section{Notes}

The authors declare no competing financial interest.

\section{ACKNOWLEDGMENTS}

J.E.B. was supported by CASE DTP PhD studentship BB/ M011208/1 from the UK Biotechnology and Biological Sciences Research Council (BBSRC) in partnership with AztraZeneca UK. We are grateful to Matthew Cliff for NMR facility management and to Grace Haagensen for assistance with HPSEC experiments.

\section{REFERENCES}

(1) Mathaes, R., Koulov, A., Joerg, S., and Mahler, H. C. (2016) Subcutaneous Injection Volume of Biopharmaceuticals-Pushing the Boundaries. J. Pharm. Sci. 105 (8), 2255-9.

(2) Jackisch, C., Muller, V., Maintz, C., Hell, S., and Ataseven, B. (2014) Subcutaneous Administration of Monoclonal Antibodies in Oncology. Geburtshilfe Frauenheilkd. 74 (4), 343-349.

(3) Viola, M., Sequeira, J., Seica, R., Veiga, F., Serra, J., Santos, A. C., and Ribeiro, A. J. (2018) Subcutaneous delivery of monoclonal antibodies: How do we get there? J. Controlled Release 286, 301-314.

(4) Stoner, K. L., Harder, H., Fallowfield, L. J., and Jenkins, V. A. (2015) Intravenous versus Subcutaneous Drug Administration. Which Do Patients Prefer? A Systematic Review. Patient 8 (2), 145-153.

(5) Liu, J., Nguyen, M. D., Andya, J. D., and Shire, S. J. (2005) Reversible self-association increases the viscosity of a concentrated monoclonal antibody in aqueous solution. J. Pharm. Sci. 94 (9), 1928-40.

(6) Scherer, T., Lilyestrom, W., Yadav, S., and Shire, S. J. (2014) Monoclonal Antibody Self-Association, Cluster Formation, and Rheology at High Concentrations. Biophys. J. 106 (2), 58a-58a.

(7) Joubert, M. K., Luo, Q., Nashed-Samuel, Y., Wypych, J., and Narhi, L. O. (2011) Classification and characterization of therapeutic antibody aggregates. J. Biol. Chem. 286 (28), 25118-33.

(8) Luo, H., Lee, N., Wang, X., Li, Y., Schmelzer, A., Hunter, A. K., Pabst, T., and Wang, W. K. (2017) Liquid-liquid phase separation causes high turbidity and pressure during low $\mathrm{pH}$ elution process in Protein A chromatography. J. Chromatogr A 1488, 57-67.

(9) Nishi, H., Miyajima, M., Nakagami, H., Noda, M., Uchiyama, S., and Fukui, K. (2010) Phase separation of an IgG1 antibody solution under a low ionic strength condition. Pharm. Res. 27 (7), 1348-60.

(10) Reiche, K., Hartl, J., Blume, A., and Garidel, P. (2017) Liquidliquid phase separation of a monoclonal antibody at low ionic strength: Influence of anion charge and concentration. Biophys. Chem. 220, 7-19.

(11) Cohen, S. L., Price, C., and Vlasak, J. (2007) Beta-elimination and peptide bond hydrolysis: two distinct mechanisms of human IgG1 hinge fragmentation upon storage. J. Am. Chem. Soc. 129 (22), 69767.

(12) Moritz, B., and Stracke, J. O. (2017) Assessment of disulfide and hinge modifications in monoclonal antibodies. Electrophoresis 38 (6), 769-785.
(13) Bye, J. W., Platts, L., and Falconer, R. J. (2014) Biopharmaceutical liquid formulation: a review of the science of protein stability and solubility in aqueous environments. Biotechnol. Lett. 36 (5), 869-75.

(14) Shire, S. J. (2009) Formulation and manufacturability of biologics. Curr. Opin. Biotechnol. 20 (6), 708-14.

(15) Wu, Y., Levons, J., Narang, A. S., Raghavan, K., and Rao, V. M. (2011) Reactive impurities in excipients: profiling, identification and mitigation of drug-excipient incompatibility. AAPS PharmSciTech 12 (4), 1248-63.

(16) Martos, A., Koch, W., Jiskoot, W., Wuchner, K., Winter, G., Friess, W., and Hawe, A. (2017) Trends on Analytical Characterization of Polysorbates and Their Degradation Products in Biopharmaceutical Formulations. J. Pharm. Sci. 106 (7), 1722-1735.

(17) Banks, D. D., Hambly, D. M., Scavezze, J. L., Siska, C. C., Stackhouse, N. L., and Gadgil, H. S. (2009) The effect of sucrose hydrolysis on the stability of protein therapeutics during accelerated formulation studies. J. Pharm. Sci. 98 (12), 4501-10.

(18) Fischer, S., Hoernschemeyer, J., and Mahler, H. C. (2008) Glycation during storage and administration of monoclonal antibody formulations. Eur. J. Pharm. Biopharm. 70 (1), 42-50.

(19) Berkowitz, S. A., Engen, J. R., Mazzeo, J. R., and Jones, G. B. (2012) Analytical tools for characterizing biopharmaceuticals and the implications for biosimilars. Nat. Rev. Drug Discovery 11 (7), 527-40.

(20) Thiagarajan, G., Semple, A., James, J. K., Cheung, J. K., and Shameem, M. (2016) A comparison of biophysical characterization techniques in predicting monoclonal antibody stability. MAbs 8 (6), 1088-97.

(21) Keire, D. A. (2019) Analytical Tools for Physicochemical Characterization and Fingerprinting. In The Science and Regulations of Naturally Derived Complex Drugs (Sasisekharan, R., Lee, S. L., Rosenberg, A., and Walker, L. A., Eds.) pp 91-113, Springer International Publishing, Cham, DOI: 10.1007/978-3-030-1175116

(22) Martinez Morales, M., Zalar, M., Sonzini, S., Golovanov, A. P., van der Walle, C. F., and Derrick, J. P. (2019) Interaction of a Macrocycle with an Aggregation-Prone Region of a Monoclonal Antibody. Mol. Pharmaceutics 16 (7), 3100-3108.

(23) Zalar, M., Svilenov, H. L., and Golovanov, A. P. (2020) Binding of excipients is a poor predictor for aggregation kinetics of biopharmaceutical proteins. Euro J. Pharm. Biopharm., DOI: 10.1016/j.ejpb.2020.04.002.

(24) Falk, B. T., Liang, Y., Bailly, M., Raoufi, F., Kekec, A., Pissarnitski, D., Feng, D., Yan, L., Lin, S., Fayadat-Dilman, L., and McCoy, M. A. (2020) NMR Assessment of Therapeutic Peptides and Proteins: Correlations That Reveal Interactions and Motions. ChemBioChem 21 (3), 315-319.

(25) Falk, B. T., Liang, Y., and McCoy, M. A. (2019) Diffusion Profiling of Therapeutic Proteins by Using Solution NMR Spectroscopy. ChemBioChem 20 (7), 896-899.

(26) Poppe, L., Jordan, J. B., Lawson, K., Jerums, M., Apostol, I., and Schnier, P. D. (2013) Profiling formulated monoclonal antibodies by (1)H NMR spectroscopy. Anal. Chem. 85 (20), 9623-9.

(27) Arbogast, L. W., Brinson, R. G., and Marino, J. P. (2016) Application of Natural Isotopic Abundance 1H-13C- and 1H-15NCorrelated Two-Dimensional NMR for Evaluation of the Structure of Protein Therapeutics. In Methods in Enzymology, pp 3-34, Academic Press, DOI: 10.1016/bs.mie.2015.09.037

(28) Brinson, R. G., Marino, J. P., Delaglio, F., Arbogast, L. W., Evans, R. M., Kearsley, A., Gingras, G., Ghasriani, H., Aubin, Y., Pierens, G. K., Jia, X., Mobli, M., Grant, H. G., Keizer, D. W., Schweimer, K., Stahle, J., Widmalm, G., Zartler, E. R., Lawrence, C. W., Reardon, P. N., Cort, J. R., Xu, P., Ni, F., Yanaka, S., Kato, K. Parnham, S. R., Tsao, D., Blomgren, A., Rundlof, T., Trieloff, N., Schmieder, P., Ross, A., Skidmore, K., Chen, K., Keire, D., Freedberg, D. I., Suter-Stahel, T., Wider, G., Ilc, G., Plavec, J., Bradley, S. A., Baldisseri, D. M., Sforca, M. L., Zeri, A. C. M., Wei, J. Y., Szabo, C. M., Amezcua, C. A., Jordan, J. B., and Wikstrom, M. (2019) Enabling 
adoption of 2D-NMR for the higher order structure assessment of monoclonal antibody therapeutics. MAbs 11 (1), 94-105.

(29) Magarian, N., Lee, K., Nagpal, K., Skidmore, K., and Mahajan, E. (2016) Clearance of extractables and leachables from single-use technologies via ultrafiltration/diafiltration operations. Biotechnol. Prog. 32 (3), 718-24.

(30) Skidmore, K., Hewitt, D., and Kao, Y. H. (2012) Quantitation and characterization of process impurities and extractables in proteincontaining solutions using proton NMR as a general tool. Biotechnol. Prog. 28 (6), 1526-33.

(31) Poppe, L., Knutson, N., Cao, S., and Wikström, M. (2019) In Situ Quantification of Polysorbate in Pharmaceutical Samples of Therapeutic Proteins by Hydrodynamic Profiling by NMR Spectroscopy. Anal. Chem. 91 (12), 7807-7811.

(32) Briggs, K. T., Taraban, M. B., and Yu, Y. B. (2018) Water proton NMR detection of amide hydrolysis and diglycine dimerization. Chem. Commun. 54 (51), 7003-7006.

(33) Taraban, M. B., DePaz, R. A., Lobo, B., and Yu, Y. B. (2017) Water Proton NMR: A Tool for Protein Aggregation Characterization. Anal. Chem. 89 (10), 5494-5502.

(34) Edwards, J. M., Bramham, J. E., Podmore, A., Bishop, S. M., van der Walle, C. F., and Golovanov, A. P. (2019) (19)F Dark-State Exchange Saturation Transfer NMR Reveals Reversible Formation of Protein-Specific Large Clusters in High-Concentration Protein Mixtures. Anal. Chem. 91 (7), 4702-4708.

(35) Kheddo, P., Cliff, M. J., Uddin, S., van der Walle, C. F., and Golovanov, A. P. (2016) Characterizing monoclonal antibody formulations in arginine glutamate solutions using (1)H NMR spectroscopy. MAbs 8 (7), 1245-1258.

(36) Liu, G., Wu, X., Jia, G., Chen, X., Zhao, H., Wang, J., Wu, C., and Cai, J. (2016) Arginine: New Insights into Growth Performance and Urinary Metabolomic Profiles of Rats. Molecules 21 (9), 1142.

(37) Sachs, D. H., Schechter, A. N., and Cohen, J. S. (1971) Nuclear magnetic resonance titration curves of histidine ring protons. I. Influence of neighboring charged groups. J. Biol. Chem. 246 (21), 6576-80.

(38) Taraban, M. B., Truong, H. C., Feng, Y., Jouravleva, E. V., Anisimov, M. A., and Yu, Y. B. (2015) Water Proton NMR for In Situ Detection of Insulin Aggregates. J. Pharm. Sci. 104 (12), 4132-4141.

(39) Hinterholzer, A., Stanojlovic, V., Cabrele, C., and Schubert, M. (2019) Unambiguous Identification of Pyroglutamate in Full-Length Biopharmaceutical Monoclonal Antibodies by NMR Spectroscopy. Anal. Chem. 91 (22), 14299-14305.

(40) Peng, J., Patil, S. M., Keire, D. A., and Chen, K. (2018) Chemical Structure and Composition of Major Glycans Covalently Linked to Therapeutic Monoclonal Antibodies by Middle-Down Nuclear Magnetic Resonance. Anal. Chem. 90 (18), 11016-11024.

(41) Dion, M. Z., Leiske, D., Sharma, V. K., Zuch de Zafra, C. L., and Salisbury, C. M. (2018) Mitigation of Oxidation in Therapeutic Antibody Formulations: a Biochemical Efficacy and Safety Evaluation of N-Acetyl-Tryptophan and L-Methionine. Pharm. Res. 35 (11), 222.

(42) Lam, X. M., Yang, J. Y., and Cleland, J. L. (1997) Antioxidants for prevention of methionine oxidation in recombinant monoclonal antibody HER2. J. Pharm. Sci. 86 (11), 1250-5.

(43) Mo, J., Jin, R., Yan, Q., Sokolowska, I., Lewis, M. J., and Hu, P. (2018) Quantitative analysis of glycation and its impact on antigen binding. MAbs 10 (3), 406-415.

(44) Wei, B., Berning, K., Quan, C., and Zhang, Y. T. (2017) Glycation of antibodies: Modification, methods and potential effects on biological functions. $m A b s 9$ (4), 586-594. 